\title{
Energy Extraction from Low Height Sea Wave in Sarawak near Shore Region
}

\author{
Man Djun Lee*, Heng Jong Ngu, Dennis Ting Yuk Shin \\ School of Engineering and Technology, University College of Technology Sarawak, Jalan Universiti, Sibu, Malaysia \\ Email: *man.djun@ucts.edu.my
}

How to cite this paper: Lee, M.D., Ngu, H.J. and Shin, D.T.Y. (2019) Energy Extraction from Low Height Sea Wave in Sarawak near Shore Region. Open Journal of Optimization, 8, 47-58. https://doi.org/10.4236/ojop.2019.81005

Received: January 29, 2019

Accepted: March 18, 2019

Published: March 21, 2019

Copyright $\odot 2019$ by author(s) and Scientific Research Publishing Inc. This work is licensed under the Creative Commons Attribution International License (CC BY 4.0).

http://creativecommons.org/licenses/by/4.0/

(c) (i) Open Access

\begin{abstract}
Generating electricity from wave is predicted to be a new source of renewable energy conversion gaining more attention and is considered in various countries as promising renewable resource. Being surrounded by sea, Malaysia has the advantage of tapping energy from the nearest sea wave. However, Malaysia has low wave climate compared to other regions. On top of that, the technologies available for extracting this energy are still in infancy stage. This study explored the potential of generating electricity from low height wave energy. The recorded average electricity can be generated from the lab scale device which is $0.224 \mathrm{~V}, 0.175 \mathrm{~A}$ and $0.039 \mathrm{~W}$. The data collected from $\mathrm{Mu}-$ kah Beach show that the maximum voltage recorded is $1.021 \mathrm{~V}$, maximum current of $0.86 \mathrm{~A}$ and highest power of $0.878 \mathrm{~W}$. By comparing results from both locations, the difference is almost 10 -fold which validates the wave maker built in laboratory with 1:10 ratio. The standard deviation of all the outputs is small which indicates that the output generation from low height wave would be consistent. Although the output is small, it could be paired together to make a larger system to generate higher output. This study concludes that the developed lab scale model is useful for harnessing electrical energy from sea wave. The future direction of research would be to optimize the current method to maximize energy capture from sea wave. Another direction for future study is to make a system comprised of a large number of such devices to generate higher output.
\end{abstract}

\section{Keywords}

Wave Energy, Point Absorber, Low Wave Height, Renewable Energy

\section{Introduction}

Wave energy power is abundant, has lower enviromental impacts and is more 
reliable than other renewable resources such as solar and wind energy due to the power density of $2-3 \mathrm{~kW} / \mathrm{m}^{2}$ (wind $0.4-0.6 \mathrm{~kW} / \mathrm{m}^{2}$; solar $0.1-0.2 \mathrm{~kW} / \mathrm{m}^{2}$ ) [1]. Generating electricity from wave is predicted to be a new source of renewable energy conversion gaining more attention and is considered in various countries as promising renewable resource [2]. With many wave energy conversion or extracting devices designed and tested, improvements are still needed in these technologies [3] [4]. On the other hand, most of the remote areas like islands are far from main power grid. Therefore, powering such areas is often considered as costly and devastating to the environment [5]. In this aspect, using wave energy as renewable energy source in such areas is desirable. Extracting wave energy has been one of the most challenging part. Technologies for harnessing this energy are still in infancy stage [6]. The significant challenge is the difficulty in slow conversion, random and high-force oscillatory motion of sea wave to generate electricity [7]. Research focus in this area is also diverse. Up to date, most research focus has been on sea performance, survival, the design and concept of primary wave interface. More detail evaluation of the complete system is necessary and efficient system is nowhere to be found [8]. Being surrounded by sea, Malaysia has the advantage of tapping energy from the nearest sea wave. Although Malaysia has low wave climate compared to other regions, the study conducted by [9] shows that Malaysia has average energy density greater than 2 $\mathrm{kW} / \mathrm{m}$, and in South East China Sea region nearby Sarawak, Malaysia has the potential to produce up to $69.41 \mathrm{MWh} / \mathrm{m}$ of energy. On this note, this study intends to design and develop a device to extract the energy from sea wave of low wave height.

\section{Literature Review}

Ocean waves are created by endless development of water under the influence of gravitational powers of sun, moon, and blowing winds. At the point when wind is sweeping across the surface of ocean, surface applies the weight on the base layer of the wind [10]. With the gravitational force being disperse at each layer, the wind strikes at different speed. The layer tumbles, shaping a roundabout movement. Thus, this makes a decreasing weight at the front and the upward weight at the back of the surface which is making a wave [11]. Waves are classified into a few areas. The peak is the most astounding point on a wave, while the trough or valley between two waves is the trivial point. Wavelength is the level division, either between the peak and troughs of two consecutive waves. Wave height, $\mathrm{H}$ is the vertical separation between a wave's peak and the following trough. Wave period, $\mathrm{T}$ measures the length of the wave in time. A wave period, $\mathrm{T}$ can be evaluated by picking a stationary point and checking the seconds it takes for two consecutive pinnacles or troughs to pass it. The repeat, $f$ is the number of pinnacles which pass a settled point in one minute. It is generally estimated in numbers every second (Hertz) and is the same as $\frac{1}{T}$. The rate of propagation, $\mathrm{c}$, is the speed at which the wave profile travels such as the 
speed at which the peak and trough of the wave progresses. It is normally referred to as wave speed or phase speed. The steepness of a wave is the ratio of the height to the length $\frac{H}{\lambda}$. Figure 1 shows the basic parameters used to describe a wave.

Kinetic and potential energy of a wave per meter of crest and unit of surface can be derived by the velocity potential which can be obtained through linear wave theory. The sum of these two energies can be analysed as shown in Equation 1 below. Hence, the wave height, $\mathrm{H}$ is equal to $2 \mathrm{~A}$. The wave period is the measurement of time taken for the wave cycle to complete, $T=\frac{\lambda}{f}$, where $\lambda$ is wavelength and $f$ is the frequency.

$$
E=\frac{\rho g A^{2}}{2}
$$

where:

$$
\begin{aligned}
& \rho=\text { water density; } \\
& g=\text { acceleration due to gravity; } \\
& A=\text { wave amplitude. }
\end{aligned}
$$

Many concepts are available to convert wave motion to electrical energy. The concepts are illustrated in Figure 2. These are: wave activated bodies (1), overtopping devices (2) and oscillating water columns (3) [13].

Wave activated bodies concept is where the motion of the wave is translated to the motion a device. A noteworthy sub class of wave activated bodies are point absorbers. The main characteristic of point absorbers is that they are small in the horizontal dimensions compared to the length of the waves from which they aim to capture energy. In other words, they take up a relatively small area of the ocean surface. This concept is the combination of the idea of Faraday's law and Newton's laws of movement together, and the considerably more settled rule of Archimedes with relative late progress in materials advancement. The magnetism of this concept is governing by Faraday's Law; with rotor wavering the connected magnetic flux $\psi$ with the copper coil will actuate in it, an electro motive force (emf) given by

$$
e(t)=-\frac{\mathrm{d} \psi}{\mathrm{d} t}
$$

generating alternating current and voltage at coil ends, which can be connected to an electric load [15].

$$
\text { voltage generated }=N \times \frac{B A}{t}
$$

where,

$$
\begin{aligned}
& N=\text { turns of the copper wire; } \\
& B=\text { magnetic field; } \\
& A=\text { cross section area; } \\
& t=\text { time. }
\end{aligned}
$$




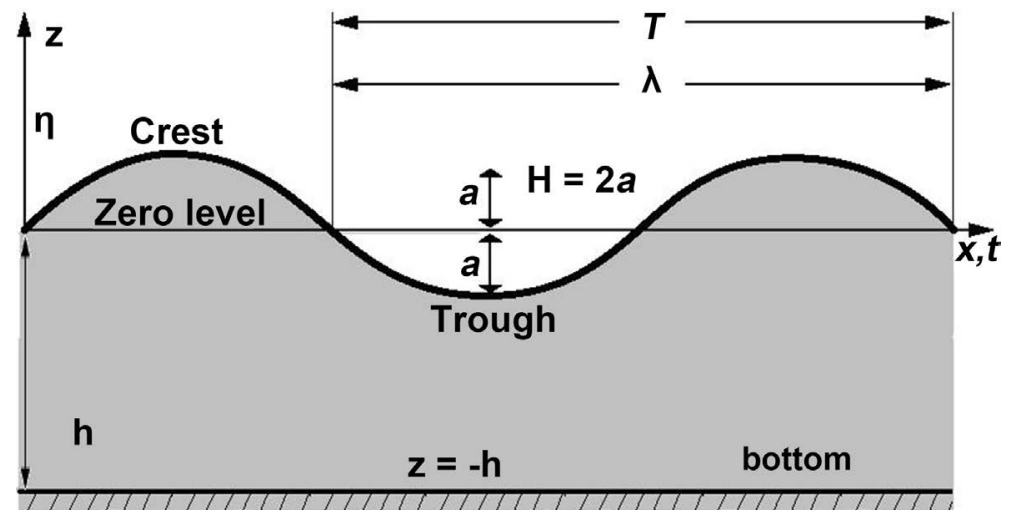

Figure 1. The parameters used to describe the wave [12].

1

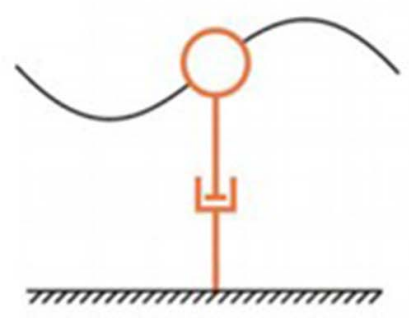

2
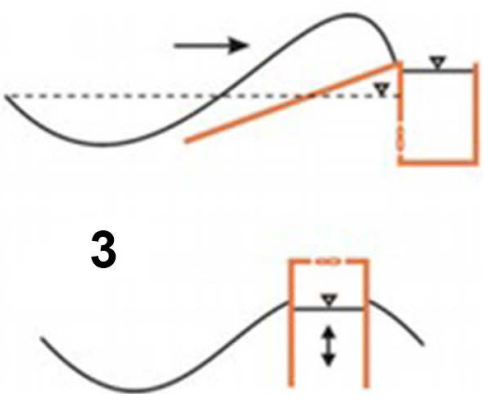

Figure 2. General concepts of capturing wave energy [14].

Overtopping devices subsist of a ramp that drives the water of approaching waves to rise and overflow into a pool. Since the water surface of the pool is higher as compared to the ocean surface, therefore energy of the waves has been converted into potential energy. In this aspect, this concept resembles hydro power plant with the water being lead back into the sea through a turbine to extract the energy [13]. As for the concept of oscillating water columns (OWCs), which consist of an oscillating pedestal of water that drives air through a turbine to generate electricity. The motion of OWC is created by taking a pipe and placing it partially under the sea. The waves that flow against the pipe will make the internal water surface oscillate. This motion is normally used to pump air which runs a turbine [11].

\section{Methodology}

This study begins with literature review for collecting latest research findings related to wave energy convertors and their findings. The conceptual model was built in the second stage of this study. Designing and developing the wave energy convertor was the third stage of this study. Final stage was conducting experiments to validate the developed lab scale model. To test the conceptual model, a lab scale model is being built. The developed lab scale model is then tested in laboratory. The methodology of this study is shown in Figure 3. 


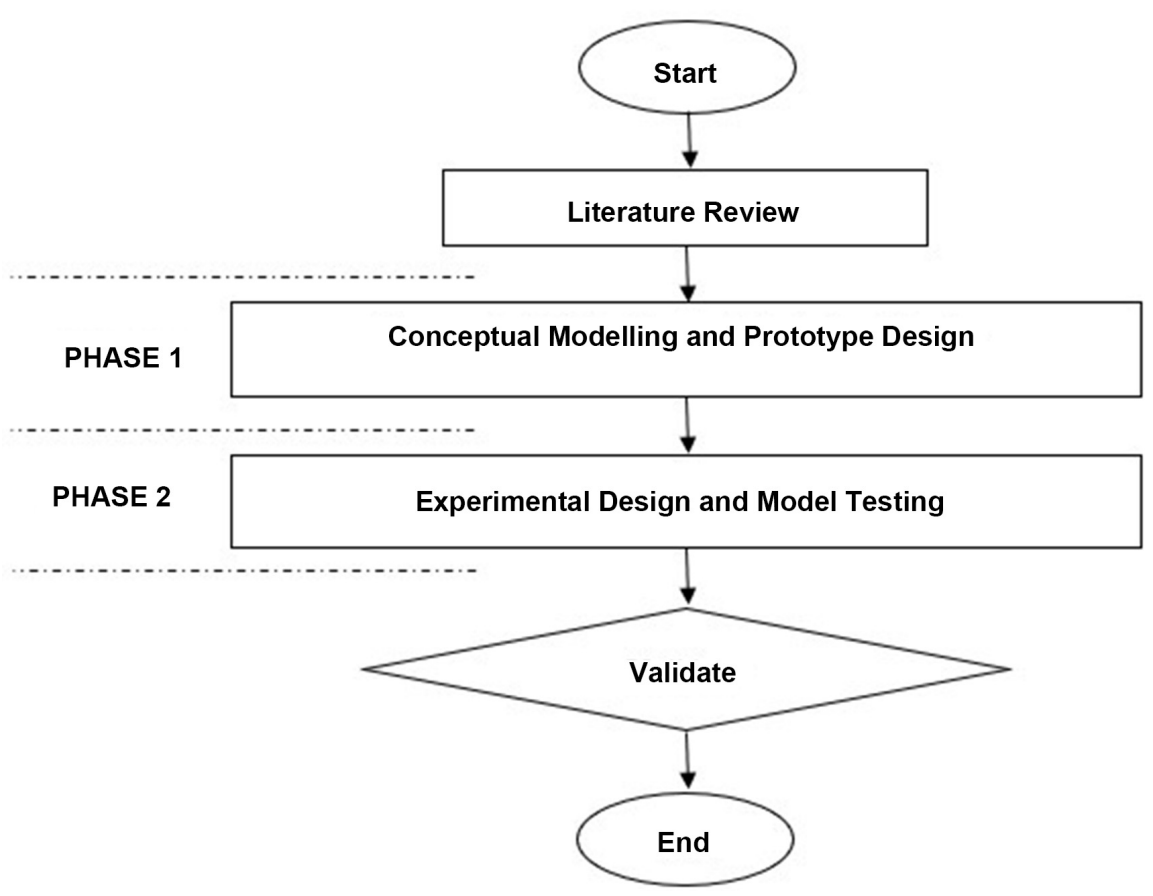

Figure 3. Research methodology.

The layout and machinery setup to test the model is shown in Figure 4. The main equipments associated with the experiment are wave maker, water tank, developed model and digital multi meter to collect data.

Wave maker is used to produce longitudinal wave to simulate low height sea wave. The wave generated by this wave maker has ratio 1:10 compared to average wave data of Sarawak, Malaysia as reported by [16]. The peak average wave height reported were in January which reached $1.56 \mathrm{~m}$ and the minimum average wave height reported were in September only reached $0.59 \mathrm{~m}$. The specification of the wave maker is shown in Table 1 . The developed lab scale model is being placed inside the tank with different wave height generated. The voltage and current generated and recorded. The technical specifications and parameters of the developed lab scale model are shown in Table 2.

\section{Results and Discussions}

The wave energy convertor utilized the float to trap the oscillating force of wave and convert it to alternating current through emf induced by stator and rotor movements. The float moves in six degrees of freedom when interacting with the body and sea wave: pitch, roll, yaw, heave, surge and sway. The movement is illustrated in Figure 5.

The generated output from lab scale model has been continuously recorded. The significant findings are recorded in Table 3. The time window of voltage, current and power are shown in Figures 6-8 respectively. Results from Table 3 indicate that extraction of energy is possible from wave with height as low as 6.4 $\mathrm{cm}$ to generate power of $0.002 \mathrm{~W}$ and voltage of $0.036 \mathrm{~V}$. The highest output 


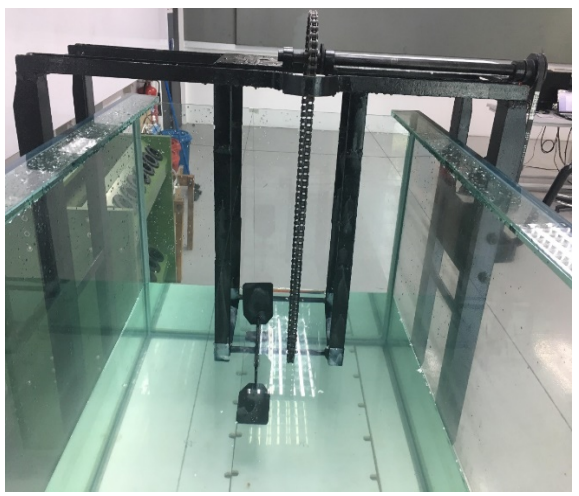

(a)

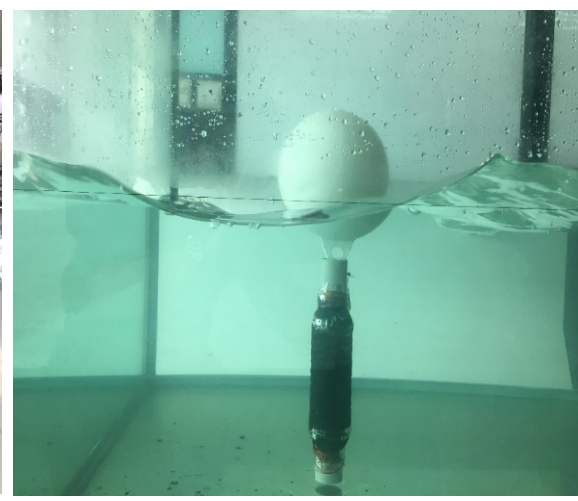

(b)

Figure 4. (a): Wave maker; (b) Developed lab scale model.

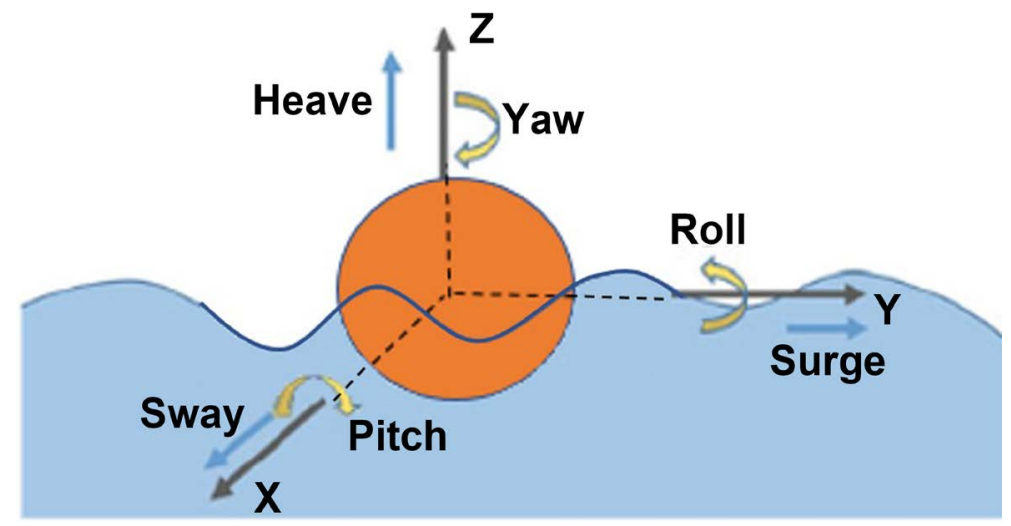

Figure 5. Degree of freedom of float when interacting with body and waves.

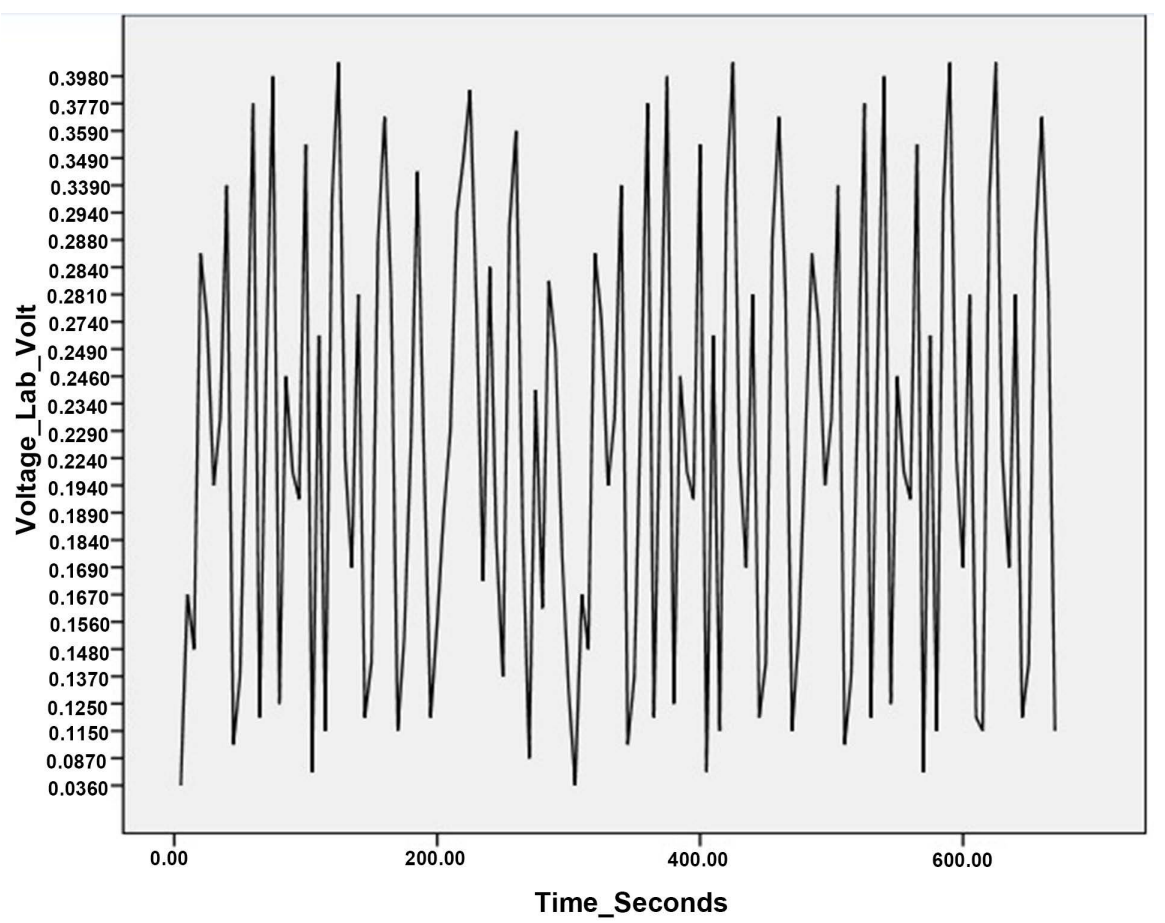

Figure 6. Voltage generated by lab scale model. 


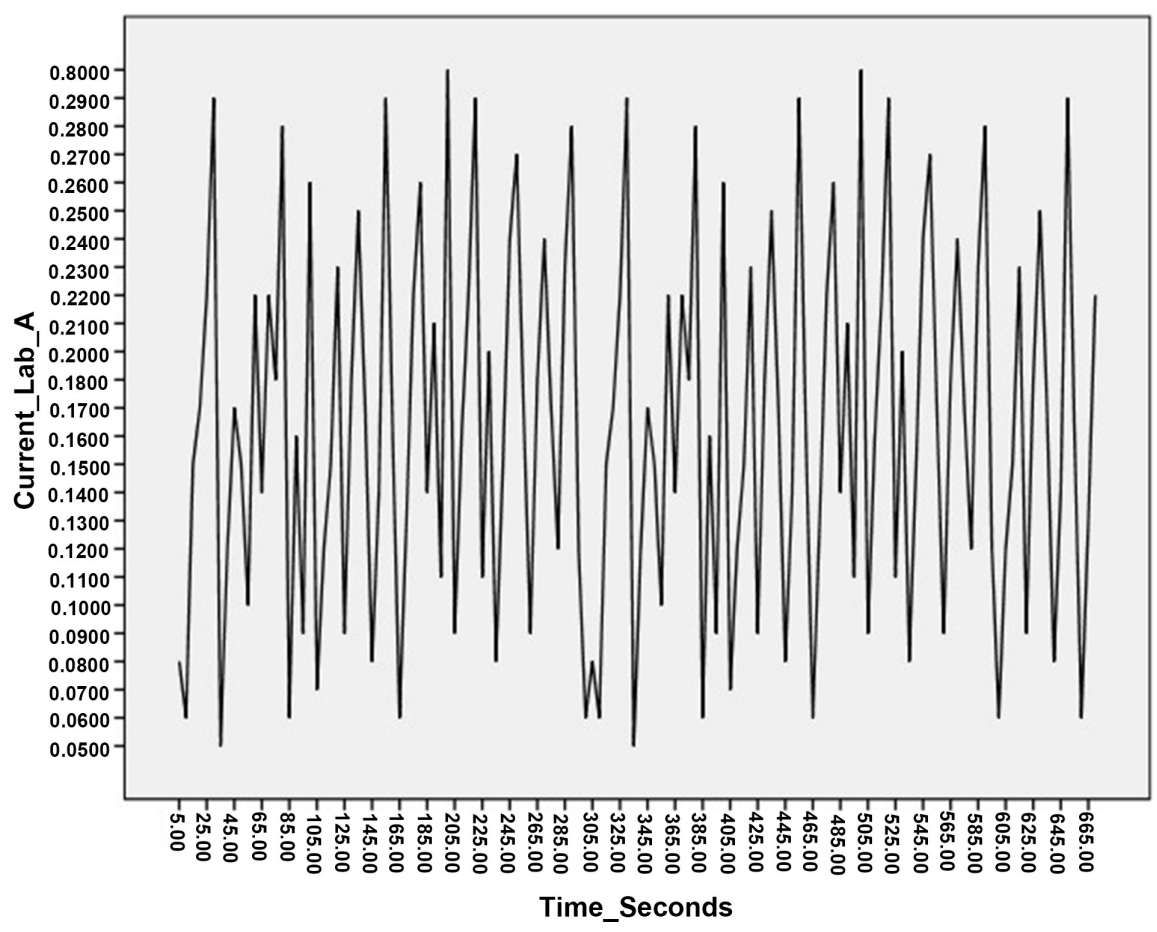

Figure 7. Current induced by lab scale model.

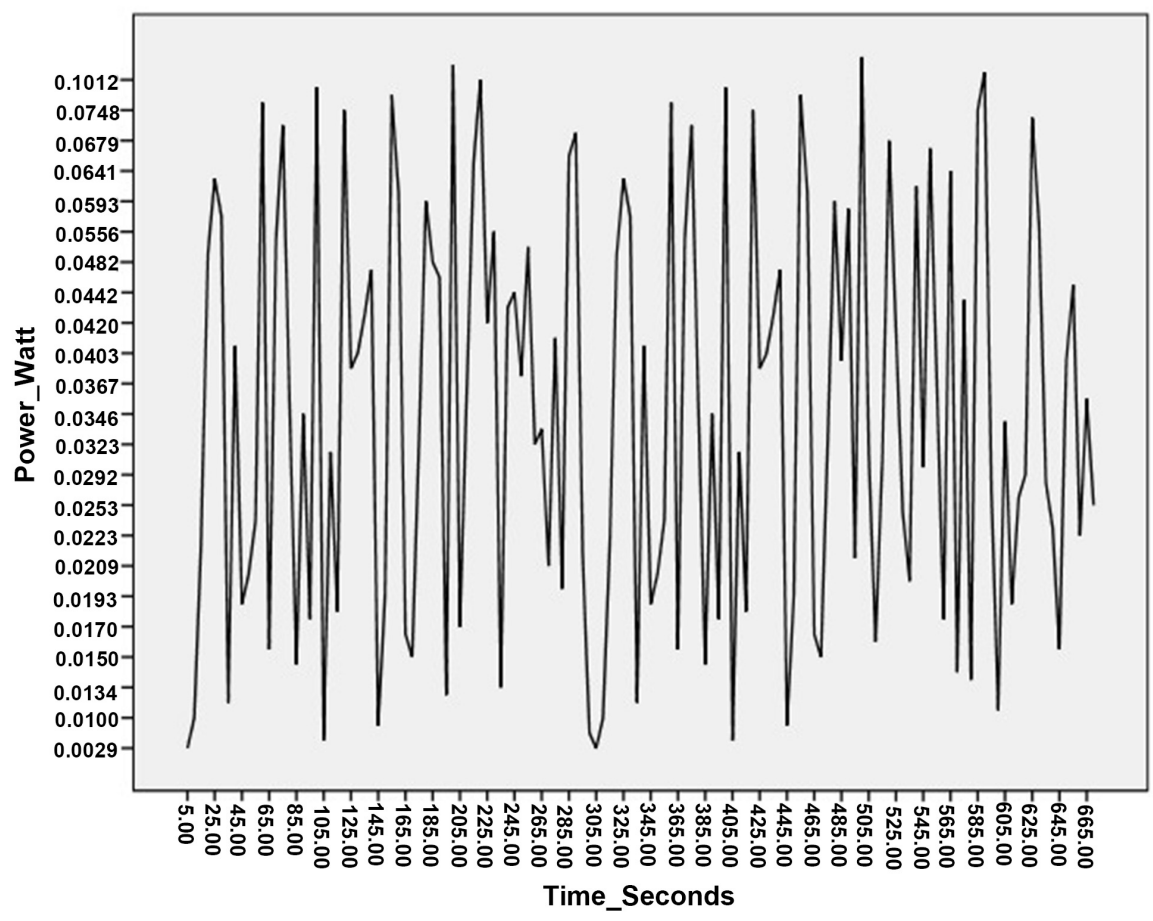

Figure 8. Power generated by lab scale model.

generated is recorded to be $0.33 \mathrm{~W}$ with voltage of $0.412 \mathrm{~V}$. The interesting part of this finding is that the standard deviation of all the collected data is relatively small. This signifies that even with small wave height, extracting energy from wave is possible and the output would be relatively consistent. Power takeoff 
Table 1. Specifications of wave maker.

\begin{tabular}{cccc}
\hline & \multicolumn{3}{c}{ Value } \\
\cline { 2 - 4 } Parameter & Min & Max & Average \\
\hline Amplitude (A) & $3.2 \mathrm{~cm}$ & $5.2 \mathrm{~cm}$ & $3.86 \mathrm{~cm}$ \\
Wave height (2A) & $6.4 \mathrm{~cm}$ & $10.4 \mathrm{~cm}$ & $7.72 \mathrm{~cm}$ \\
Wavelength ( $\lambda$ ) & $9 \mathrm{~cm}$ & $14 \mathrm{~cm}$ & $11.3 \mathrm{~cm}$ \\
Frequency (f) & $0.025 \mathrm{~Hz}$ & $0.026 \mathrm{~Hz}$ & $0.026 \mathrm{~Hz}$ \\
\hline
\end{tabular}

Table 2. Specifications of lab scale model and parameters.

\begin{tabular}{cc}
\hline Parameter & Value \\
\hline Density of seawater, $\rho$ & $1025 \mathrm{~kg} / \mathrm{m}^{3}$ \\
Standard acceleration due to gravity, $g .81 \mathrm{~m} / \mathrm{s}^{2}$ & $28 \mathrm{~cm}$ \\
Water depth in tank & \\
\hline Floating ball & $0.1 \mathrm{~kg}$ \\
\hline Mass of buoy, Mb & $14.0 \mathrm{~cm}$ \\
Inner radius of buoy & $14.5 \mathrm{~cm}$ \\
Outer radius of buoy & $14.5 \mathrm{~cm}$ \\
Height of buoy & \\
Generator & $427.5 \mathrm{~m}$ \\
\hline Length of copper wire & $4050 \mathrm{turns}$ \\
Turn of copper wire & $0.5 \mathrm{~mm}$ \\
Copper wire thickness & 15 layer \\
Roll of layer &
\end{tabular}

Table 3. Output generated at Makah Beach by wave energy conversion device.

\begin{tabular}{ccccc}
\hline \multirow{2}{*}{ Outputs } & \multicolumn{3}{c}{ Value } & \multirow{2}{*}{ Std. deviation } \\
\cline { 2 - 4 } & Min & Max & Average & \\
\hline Voltage (V) & 0.036 & 0.412 & 0.224 & 0.092 \\
Current (A) & 0.050 & 0.800 & 0.175 & 0.107 \\
Power (W) & 0.002 & 0.330 & 0.039 & 0.026 \\
\hline
\end{tabular}

system is needed to improve energy generation performance of such system. The example system that could be implemented with such system is shown in Figure 9. Since most wave energy study in Malaysia are in conceptual phase, there is no significant comparison or validation can be made to compare findings from this study [16] [17] [18]. Other studies focus on extracting energy in high wave height or built in large scale with expecting large output generated from the devices [3] [19] [20]. The advantage of this type of system is that it can harvest energy from waves in all directions at one point in the ocean. It can be placed at 


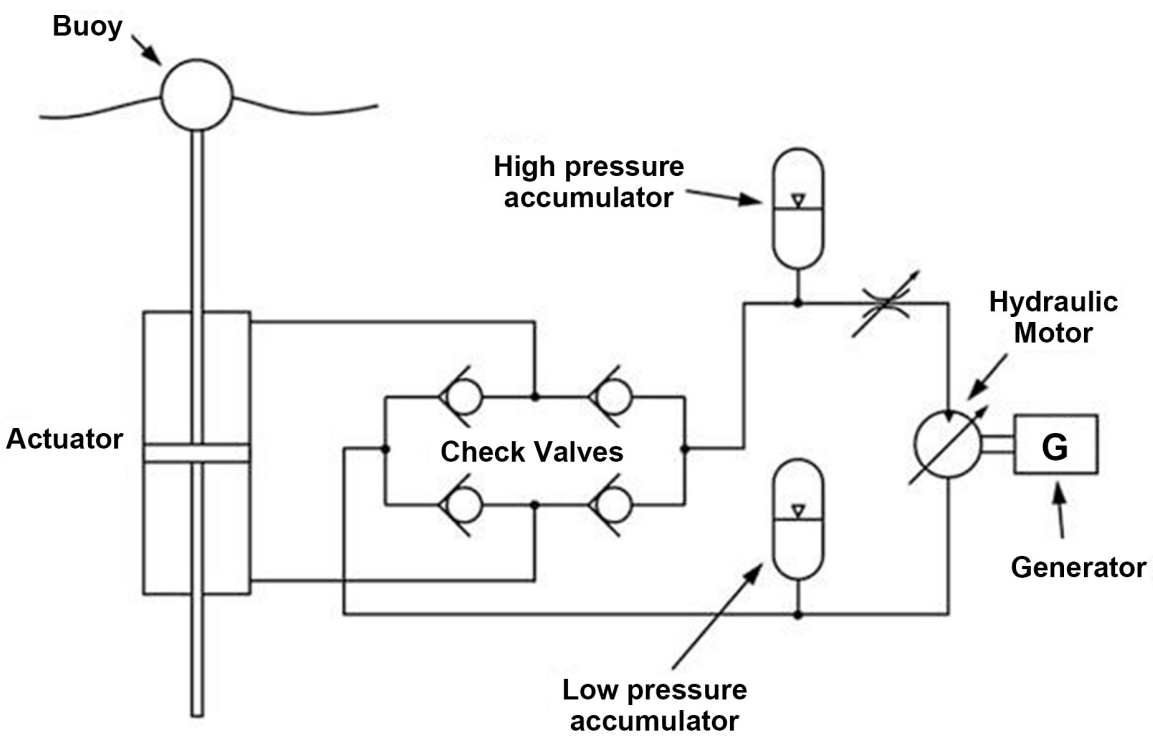

Figure 9. Example of a hydraulic power takeoff system for wave energy convertor.

or near the ocean surface away from the shoreline and may occupy a variety of ocean depths ranging from shallow to very deep water depending on the design and the mooring system.

The aim of this study is to produce wave energy convertor to be able to generate electricity from wave. The models are tested in laboratory and beach in $\mathrm{Mu}-$ kah, Sarawak. The results generated from both locations were consistent. However, by comparing results from both locations, the difference is more than 10-fold which validated the wave maker built in laboratory with 1:10 ratio. The advantage of using this type of wave energy convertor is that the area needed is small and there is no significant negative impact towards marine ecosystem within the extraction area. However, the limitation of this study is that it did not pair it with power takeoff system to store the electricity generated. On the other hand, energy generation from wave is presently too costly to be even considered as renewable energy. The costings of energy generation from wave are classified into: production, installation, maintenance, and power takeoff system. Due to the nature of variation in costings between different modes of extraction, it is not easy to determine the cost of production for wave energy conversion system. As an example, the cost of connecting electrical grid from shoreline is definitely lower compared to offshore convertors because less electrical cable to be installed and maintained. In addition, installation and maintenance costs are much higher for offshore conversion systems than shoreline since the offshore ones are more difficult to access. However, for future study, the focus is likely to reduce cost to a significant level to make it sustainable. Continuation of current study will most possibly generate more cheap and efficient devices that will bring down total production costs. Similarly, current studies in the field of ocean engineering focus on producing devices in limited quantity for research purposes. If produce large enough, the economy of scale will contribute to lowering the 
overall production cost and making this technology sustainable in the long run.

\section{Conclusion}

Wave energy is an alternative source of renewable energy that would contribute to tackling world energy crisis. Wave energy would be useful for countries that are surrounded by sea, particularly Malaysia. However, extracting wave energy has been one of the most challenging parts as most technologies for extracting this energy are still in infancy stage. This study explored the potential of generating electricity from low height wave energy. The recorded average electricity can be generated from the lab scale device which is $0.224 \mathrm{~V}, 0.175 \mathrm{~A}$ and $0.039 \mathrm{~W}$. The data collected from Mukah Beach show that the maximum voltage recorded is $1.021 \mathrm{~V}$, maximum current of $0.86 \mathrm{~A}$ and highest power of $0.878 \mathrm{~W}$. By comparing results from both locations, the difference is almost 10-fold which validates the wave maker built in laboratory with 1:10 ratio. The standard deviation of all the outputs is small which indicates that the output generation from low height wave would be consistent. Although the output is small, it could be paired together to make a larger system to generate higher output. This study concludes that the developed lab scale model is useful for harnessing electrical energy from sea wave. The future direction of research would be to optimize the current method to maximize energy capture from sea wave. Another direction for future study is to make a system comprised of a large number of such devices to generate higher output.

\section{Acknowledgements}

The authors acknowledge the financial support received from University College of Technology Sarawak, Malaysia under university internal grant scheme (UCTS/research/4/2017/2). Authors are also pleased to offer special thanks to staffs of School of Engineering for their support.

\section{Conflicts of Interest}

The authors declare no conflicts of interest regarding the publication of this paper.

\section{References}

[1] Ramos, V., López, M., Taveira-Pinto, F. and Rosa-Santos, P. (2017) Influence of the Wave Climate Seasonality on the Performance of a Wave Energy Converter: A Case Study. Energy, 135, 303-316. https://doi.org/10.1016/j.energy.2017.06.080

[2] Lisboa, R.C., Teixeira, P.R.F. and Fortes, C.J. (2017) Numerical Evaluation of Wave Energy Potential in the South of Brazil. Energy, 121, 176-184. https://doi.org/10.1016/j.energy.2017.01.001

[3] Joe, H., Roh, H., Cho, H. and Yu, S.C. (2017) Development of a Flap-Type Mooring-Less Wave Energy Harvesing System for Sensor Buoy. Energy, 133, 851-863. https://doi.org/10.1016/j.energy.2017.05.143

[4] Fadaeenejad, M., Shamsipour, R., Rokni, S.D. and Gomes, C. (2014) New Ap- 
proaches in Harnessing Wave Energy: With Special Attention to Small Islands. Renewable \& Sustainable Energy Reviews, 29, 345-354.

https://doi.org/10.1016/j.rser.2013.08.077

[5] Shatat, M., Worall, M. and Riffat, S. (2013) Economic Study for an Affordable Small Scale Solar Water Desalination System in Remote and Semi-Arid Region. Renewable \& Sustainable Energy Reviews, 25, 543-551.

https://doi.org/10.1016/j.rser.2013.05.026

[6] Mirzaei, A., Tangang, F. and Juneng, L. (2015) Wave Energy Potential Assessment in the Central and Southern Regions of the South China Sea. Renewable Energy, 80, 454-470.

[7] Gray, A., Dickens, B., Bruce, T., Ashton, I. and Johanning, L. (2017) Reliability and O\&amp; M Sensitivity Analysis as a Consequence of Site Specific Characteristics for Wave Energy Converters. Ocean Engineering, 141, 493-511. https://doi.org/10.1016/j.oceaneng.2017.06.043

[8] Lehmann, M., Karimpour, F., Goudey, A. and Jacobson, P.T. (2016) Ocean Wave Energy in the United States: Current Status and Future Perspectives. Renewable and Sustainable Energy Reviews, 74, 1300-1313.

[9] Yaakob, O., Hashim, F., Omar, K., Din, A. and Koh, K. (2016) Satellite-Based Wave Data and Wave Energy Resource Assessment for South China Sea. Renewable Energy, 88, 359-371.

[10] Leijon, M. et al. (2006) An Electrical Approach to Wave Energy Conversion. Renewable Energy, 31, 1309-1319. https://doi.org/10.1016/j.renene.2005.07.009

[11] Wang, Y. and Wang, L. (2018) Towards Realistically Predicting the Power Outputs of Wave Energy Converters: Nonlinear Simulation. Energy, 144, 120-128. https://doi.org/10.1016/j.energy.2017.12.023

[12] Mohamed, A. and Saad, E. (2010) Wave and Wind Conditions in the Red Sea: A Numerical Study Using a Third Generation Wave Model.

[13] Pecher, A. (2017) Handbook of Ocean Wave Energy. Springer, Switzerland, Vol. 7. https://doi.org/10.1007/978-3-319-39889-1

[14] Kim, S.-J., Koo, W. and Shin, M.-J. (2018) Numerical and Experimental Study on a Hemispheric Point-Absorber-Type Wave Energy Converter with a Hydraulic Power Take-Off System. Renewable Energy, 135, 1260-1269.

[15] Venugopal, V., Nemalidinne, R. and Vögler, A. (2017) Numerical Modelling of Wave Energy Resources and Assessment of Wave Energy Extraction by Large Scale Wave Farms. Ocean \& Coastal Management, 147, 37-48. https://doi.org/10.1016/j.ocecoaman.2017.03.012

[16] Samrat, N.H., Bin Ahmad, N., Choudhury, I.A. and Taha, Z. (2014) Prospect of Wave Energy in Malaysia. 2014 IEEE 8th International Power Engineering and OPtimization Conference (PEOCO2014), Langkawi, 15 March 2014, 127-132. https://doi.org/10.1109/PEOCO.2014.6814412

[17] Mohd Nasir, N.A. and Maulud, K.N.A. (2016) Wave Power Potential in Malaysian Territorial Waters. IOP Conference Series: Earth and Environmental Science, 37, 12-18.

[18] Loon, S.C. and Koto, J. (2016) Wave Energy for Electricity Generation in Malaysia-Merang Shore, Terengganu. International Journal of Energy and Environment, 304, 8-18.

[19] Whittaker, T., Collier, D., Folley, M., Osterried, M., Henry, A. and Crowley, M. (2007) The Development of Oyster-A Shallow Water Surging Wave Energy Con- 
verter. Proceedings of 7 th European Wave Tidal Energy Conference, Porto, 11 September 2007, 11-14.

[20] Wang, L., Isberg, J. and Tedeschi, E. (2018) Review of Control Strategies for Wave Energy Conversion Systems and Their Validation: The Wave-to-Wire Approach. Renewable \& Sustainable Energy Reviews, 81, 366-379. 